\title{
Long-term follow-up of toluene diisocyanate-induced asthma
}

\author{
M. Padoan*, V. Pozzato*, M. Simoni", L. Zedda*, G. Milan*, I. Bononi", C. Piola ${ }^{+}$, P. Maestrelli*, \\ P. Boschetto', C.E. Mapp
}

Long-term follow-up of toluene diisocyanate-induced asthma. M. Padoan, V. Pozzato, M. Simoni, L. Zedda, G. Milan, I. Bononi, C. Piola, P. Maestrelli, P. Boschetto, C.E. Mapp. C ERS Journals Ltd 2003.

ABSTRACT: Eighty-seven cases of occupational asthma induced by toluene diisocyanate (TDI) were diagnosed by an inhalation challenge with TDI and methacholine. After an average follow-up interval of $11 \mathrm{yrs}$, all subjects were re-examined.

Of the 87 subjects examined, $13(15 \%)$ had remained in the same job, $44(50.5 \%)$ had been removed from exposure for $<10$ yrs and $30(34.5 \%)$ had been removed for $>10$ yrs. The proportion of subjects who experienced symptoms of asthma and those who were hyperresponsive to methacholine was significantly lower. Of the patients, $59 \%$ used short-acting bronchodilators, $8 \%$ long-acting bronchodilators and $18 \%$ were on regular inhaled glucocorticoids. Thus, multiple regression analysis showed a positive correlation between forced vital capacity (FVC) and forced expiratory volume in one second (FEV1) at follow-up and FVC and FEV1 at diagnosis, and a negative correlation with smoking and with therapy with bronchodilators. Stepwise logistic regression showed that the follow-up provocative dose causing a 20\% fall in the FEV1 (PD20) could be predicted from baseline PD20.

These results indicate that respiratory symptoms and airway hyperresponsiveness to methacholine persist in subjects removed from exposure to TDI for $>10$ yrs. A more favourable prognosis was associated with a better lung function and a lower degree of airway hyperresponsiveness to methacholine at diagnosis. Eur Respir J 2003; 21: 637-640.

\begin{abstract}
*Dept of Environmental Medicine and Public Health, University of Padua, Padua, ${ }^{\#}$ National Research Council of Pisa, Pisa, "Dept of Experimental and Clinical Medicine, Section of Occupational Medicine, University of Ferrara, Ferrara, ${ }^{+}$Depts of Medicine, Oncology and Radiology, Section of Respiratory Diseases, University of Modena, Modena, Italy.
\end{abstract}

Correspondence: C.E. Mapp, Dipartimento di Medicina Clinica e Sperimentale, Sezione di Igiene e Medicina del Lavoro, Via Fossato di Mortara 64/b, 44100 Ferrara, Italy.

Fax: 390532205066

E-mail: map@unife.it

Keywords: Isocyanates, methacholine, occupational asthma, outcome.

Received: July 92002

Accepted after revision: November 292002

This study was supported in part by grants from MURST $(60 \%$ and $40 \%)$, A.R.C.A. and Consorzio Ferrararicerche.
Diisocyanates, widely used and highly reactive industrial chemicals, are among the most frequent causes of occupational asthma (OA) in industrialised countries [1]. The most commonly used diisocyanate is toluene diisocyanate (TDI), a mixture of 2,4 and 2,6 isomers (80:20). The precise mechanisms underlying isocyanate-induced asthma are unknown, even though the immunological mechanism remains the likeliest occurrence, with its latency interval between exposure and onset of asthma [2]. In terms of long-term outcome, despite complete avoidance of exposure, PARK and NAHM [3] showed a spectrum of responses in subjects with isocyanate asthma and proposed that the final outcome depends on which mechanism is predominant in each individual. The majority of the follow-up studies on isocyanate asthma [4-11] emphasised that only one-half of subjects with isocyanate asthma will recover, while one-half of those who do not recover will show some improvement, and one-half will complain of asthmatic symptoms and will require anti-asthma therapy. Short duration of exposure to isocyanates and of symptoms before the diagnosis, immediate cessation of exposure after diagnosis, young age, milder degree of nonspecific airway hyperresponsiveness and presence of specific immunoglobulin (Ig)E antibodies to isocyanates have been found to be associated with a favourable prognosis.

In the present study, the results of a follow-up examination on 87 subjects sensitised to TDI are reported. The phenotype characteristics of the subjects are illustrated in order to investigate the outcome of disease. Since OA is a valid model of adult-onset asthma [12,13], information on the outcome of OA can also bring new insights into the natural history of non-OA.

\section{Methods}

Eighty-seven subjects with a history of asthma induced by exposure to TDI were studied. None of these subjects had symptomatic asthma before occupational exposure to TDI or had been subject to exposure to isocyanate spills in the past. All subjects were asked for a detailed clinical and occupational history, and underwent skin-prick tests with a battery of common allergens and pulmonary function tests. All subjects had been free of respiratory infections or exposure to isocyanates for at least 2 weeks. No subject had taken cromolyn, theophylline, sympathomimetics or antihistamines within $48 \mathrm{~h}$ of any study. Forced vital capacity (FVC) and forced expiratory volume in one second (FEV1) were measured using a dry bellows spirometer (Model 840; Ohio Air Co., Houston, TX, USA). The isocyanate inhalation test was carried out in all subjects at the time of diagnosis. The methacholine inhalation challenge was performed at diagnosis and at a follow-up visit, as previously described [14]. Thirty subjects did not perform the inhalation challenge with methacholine at follow-up for the following reasons: 18 exhibited airway obstruction, two had expiratory wheezes at chest auscultation, seven had hypertension, one was breastfeeding, one had paradoxic bronchoconstrictor response to bronchodilators and one refused to perform the challenge. 
The instruments, methods and technicians were the same at diagnosis and the follow-up visit.

\section{Data analysis}

An asthmatic reaction to TDI was considered to occur when FEV 1 decreased by at least $20 \%$ from baseline. Airway obstruction was defined as $\mathrm{FEV} 1 / \mathrm{FVC}$ ratio $<75 \%$ according to the criteria established by the American Thoracic Society [15]. To assess airway responsiveness, the cumulative dose of methacholine producing a $20 \%$ fall in the FEV1 (PD20) was calculated by interpolation from the dose/response curve and was used as a measure of airway responsiveness.

The following statistical analyses were carried out: frequency distribution, Kolmogorov-Smirnov nonparametric test for normality, nonparametric test of Mann-Whitney, Chi-squared test, correlation, and multiple regression analysis. Since distribution of methacholine was highly skewed, $\log 10$ transformation was used for statistical analysis and values were reported as geometric means.

A stepwise logistic regression was performed to evaluate the effects of potential factors (independent variables: baseline responsiveness $(\log$ PD20), duration of exposure (yrs), length of follow-up (yrs), absence or presence of current inhaled glucocorticoids on the follow-up airway responsiveness abnormal PD20 ( $\leqslant 1 \mathrm{mg}$ versus normal PD20 >1 mg) (dependent variable). Length of follow-up was put into the model as a continuous or categorical ( $\geqslant 10 \mathrm{yrs},<10 \mathrm{yrs}$ ) variable.

A $p \leqslant 0.05$ was considered to be significant.

\section{Results}

The clinical features of the subjects at the time of diagnosis and of the follow-up visit are shown in table 1. There were 63 males and 24 females included in the study. A small proportion of the subjects were smokers and atopics, features that did not change at the follow-up visit. The average duration of exposure to TDI was $12 \mathrm{yrs}$. The majority of workers $(>70 \%)$ were employed in furniture factories or carpentry shops. At follow-up visit (average duration of follow-up \pm SEM: $11 \pm 0.4 \mathrm{yrs}$ ), $15 \%$ of the subjects continued to remain exposed to TDI, whereas $85 \%$ had been removed from exposure. Of those removed from exposure, $34.5 \%$ had been removed for $>10$ yrs. There was a significant difference with regard to the presence of symptoms of asthma and of airway hyperresponsiveness to methacholine between the two visits, with a lower percentage of symptomatic (71 versus $100 \%)$ and hyperresponsive subjects (25 versus $62.5 \%$ ) at follow-up $(\mathrm{p}<0.001)$. When subjects were examined according to the interval since removal from exposure, respiratory symptoms occurred in $84.6 \%$ of subjects exposed to TDI, in $75 \%$ of those removed for $<10$ yrs $(\mathrm{p}<0.001)$ and in $60 \%$ of those removed for $>10$ yrs $(p<0.01)$. PD20 methacholine was lower in subjects exposed to TDI at follow-up (geometric $(G)$ mean (GSEM) 0. $855 \mathrm{mg}$ (1.46) versus $1.045 \mathrm{mg}$ (1.15) in subjects removed for $<10$ yrs and $1.173 \mathrm{mg}$ (1.18) in those removed for $>10$ yrs. The degree of airway responsiveness was milder at follow-up examination. At diagnosis, 35.6\% of subjects with a positive inhalation challenge to methacholine had a PD20 $<0.300 \mathrm{mg}$, whereas at follow-up the percentage of subjects highly responsive to methacholine was $8.9 \%$. At follow-up visit, $59 \%$ of the subjects used inhaled short-acting bronchodilators, $8 \%$ used long-acting bronchodilators and $18 \%$ used inhaled glucocorticoids. At the time of the diagnosis, specific inhalation challenge with TDI in the laboratory elicited an immediate asthmatic reaction in $20.7 \%$, a late
Table 1.-Characteristics of 87 subjects with toluene diisocyanate (TDI) asthma at the time of diagnosis and the follow-up visit

\begin{tabular}{lcr}
\hline & Diagnosis & Follow-up \\
\hline Age yrs & $38.0 \pm 1.2$ & $48.7 \pm 1.2^{\#}$ \\
Sex & & \\
$\quad$ Male & 63 & \\
$\quad$ Female & 24 & \\
Smoking habits & & \\
$\quad$ Nonsmoker & $63.2 \%$ & $63.2 \%$ \\
$\quad$ Exsmoker & $28.7 \%$ & $29.9 \%$ \\
$\quad$ Current smoker & $8.0 \%$ & $6.9 \%$ \\
Atopic status & $23.0 \%$ & $28.7 \%$ \\
Duration of exposure yrs & $12.0 \pm 0.9$ & \\
Duration of symptoms yrs & $3.8 \pm 0.5$ & \\
Current exposure & & $15.0 \%$ \\
$\quad$ Yes & & $85.0 \%$ \\
$\quad$ No & & $71.0 \%$ \\
Symptoms of asthma & $100 \%$ & \\
Type of asthmatic reaction & & \\
Immediate & $20.7 \%$ & \\
$\quad$ Late alone & $54.0 \%$ & \\
Dual & $25.3 \%$ & \\
\hline
\end{tabular}

Data are presented as mean \pm SEM unless otherwise stated. \#: significantly different from age of diagnosis by use of MannWhitney test, $\mathrm{p}<0.001$; : : significantly different from symptoms at diagnosis by use of the Chi-squared test, $\mathrm{p}<0.001$.

reaction in $54 \%$ and a dual reaction in $25.3 \%$ of the subjects. At the time of the follow-up examination, there was a significant difference in FVC (\% predicted) and PD20 methacholine, as compared with values obtained at diagnosis (table 2) [16]. Among subjects exposed to TDI, 33.3\% at diagnosis and $37.9 \%$ at follow-up exhibited airway obstruction. At follow-up examination, the lung volumes FEV1 (L) and/or FEV1 \% pred, and FVC (L) and/or FVC \% pred, and PD20 methacholine showed a negative correlation with the duration of exposure to TDI, but the correlations were significant only for subjects exposed to TDI. Spearman's rank correlations were $-0.70, \mathrm{p}<0.01 ;-0.65, \mathrm{p}<0.05 ;-0.55, \mathrm{p}<0.05$; $-0.49,1<\mathrm{p}<0.05$; and $-0.60, \mathrm{p}<0.05$, respectively.

Multiple regression analysis showed that follow-up FEV1 ( $\%$ pred) and FVC ( $\%$ pred) values could be predicted from those at diagnosis. At the time of follow-up examination, FEV1 and FVC were significantly lower in smokers $(B=-6.38$,

Table 2. - Respiratory parameters measured at diagnosis and the follow-up visit

\begin{tabular}{lcc}
\hline & Diagnosis & Follow-up \\
\hline FVC \% pred & $98.1 \pm 1.2^{\uparrow}$ & $94.4 \pm 1.4^{\S}$ \\
FEV1 \% pred & $98.8 \pm 1.6$ & $98.1 \pm 1.7$ \\
FEV1/FVC ratio & $77.4 \pm 0.8$ & $77.1 \pm 0.7$ \\
Airway obstruction & $33.3 \%$ & $37.9 \%$ \\
FEV1/FVC $<75 \%$ & $0.466(1.12)^{+}$ & $1.042(1.11)^{f}$ \\
PD20 mg &
\end{tabular}

FVC: forced vital capacity; FEV1: forced expiratory volume in one second; PD20: provocative dose of methacholine causing a $20 \%$ fall in FEV1. \#: criteria from the American Thoracic Society, 1986 [15]; ${ }^{\top}$ : predicted values from Commissions des Communautes Europeennes [16]; ${ }^{+}$: geometric (G) mean and GSEM; ${ }^{\S}$ : significantly different from FVC ( $\%$ pred $)$ at diagnosis, by use of Mann-Whitney test, $\mathrm{p}<0.05,{ }^{f}$ : significantly different from PD20 at diagnosis by use of Mann-Whitney test, $\mathrm{p}<0.001$. 
$\mathrm{p}<0.005$ and $\mathrm{B}=-5.53, \mathrm{p}<0.005$, respectively), whereas atopy was associated with a better lung function $(B=4.64, p<0.05$ and $\mathrm{B}=5.21, \mathrm{p}<0.001$, respectively). FEV1 (\% pred) was lower in symptomatic subjects $(B=-7.61, p<0.005)$. The results of the stepwise multivariate logistic regression are shown in table 3. In all models, PD20 at diagnosis was a significant predictor of follow-up PD20, a lower degree of airway hyperresponsiveness to methacholine at diagnosis being associated with a lower risk to be hyperresponsive at follow-up. The duration of exposure, the interval since removal from exposure and the current treatment with inhaled glucocorticoids were predictors of the responsiveness to methacholine at the follow-up visit, but the significance was borderline $(p=0.06, p=0.08$ and $\mathrm{p}=0.06$, respectively).

Table 3.-Summary of the stepwise logistic regression analysis for the effects of initial provocative dose causing a $20 \%$ fall in the forced expiratory volume in one second (PD20), duration of exposure, duration of follow-up and treatment with inhaled steroids among subjects with PD20 $\leqslant 1 \mathrm{mg}$ and $>1 \mathrm{mg}$ at follow-up

\begin{tabular}{|c|c|c|c|c|}
\hline Variable & Model 0 & Model 1 & Model 2 & Model 3 \\
\hline \multicolumn{5}{|l|}{$\begin{array}{l}\text { Initial PD20, } \\
\text { log dose }\end{array}$} \\
\hline $\mathrm{B}$ & -2.422 & -2.313 & -3.42 & -2.14 \\
\hline $\mathrm{SE}$ & 1.039 & 1.049 & 1.384 & 1.070 \\
\hline OR & 0.08 & 0.09 & 0.03 & 0.11 \\
\hline CI & $0.01-0.68$ & $0.01-0.77$ & $0.002-0.49$ & $0.01-0.95$ \\
\hline p-value & 0.02 & 0.02 & 0.01 & 0.04 \\
\hline \multicolumn{5}{|l|}{$\begin{array}{l}\text { Duration of } \\
\text { exposure, yrs }\end{array}$} \\
\hline B & -0.08 & -0.08 & -0.13 & -0.10 \\
\hline $\mathrm{SE}$ & 0.060 & 0.061 & 0.071 & 0.074 \\
\hline OR & 0.91 & 0.92 & 0.87 & 0.90 \\
\hline CI & $0.81-1.03$ & $0.81-1.04$ & $0.76-1.01$ & $0.78-1.04$ \\
\hline p-value & 0.16 & 0.19 & 0.06 & 0.16 \\
\hline $\begin{array}{l}\text { Last exposure } \\
\text { to TDI yrs }\end{array}$ & NI & & NI & \\
\hline B & & 0.04 & & 0.03 \\
\hline $\mathrm{SE}$ & & 0.089 & & 0.102 \\
\hline OR & & 1.04 & & 1.03 \\
\hline CI & & $0.87-1.24$ & & $0.84-1.26$ \\
\hline p-value & & 0.11 & & 0.72 \\
\hline $\begin{array}{l}\text { Interval since } \\
\text { removal from } \\
\text { exposure yrs } \\
(\geqslant 10<10)\end{array}$ & & & & NI \\
\hline B & & & 2.02 & \\
\hline $\mathrm{SE}$ & & & 1.172 & \\
\hline OR & & & 7.59 & \\
\hline CI & & & $0.76-75.6$ & \\
\hline p-value & & & 0.08 & \\
\hline \multicolumn{5}{|l|}{$\begin{array}{l}\text { Current inhaled } \\
\text { steroids, yes } \\
\text { versus no }\end{array}$} \\
\hline B & & & & 2.22 \\
\hline $\mathrm{SE}$ & & & & 1.211 \\
\hline OR & & & & 9.22 \\
\hline CI & & & & 0.85-99.08 \\
\hline p-value & & & & 0.06 \\
\hline Prediction & 82.9 & 82.9 & 87.2 & 82.9 \\
\hline
\end{tabular}

\#: dependent variable, PD20 $\leqslant 1 \mathrm{mg}$. Model: NI: variable not included in the model; 0: normal airway responsiveness (PD20 > $1 \mathrm{mg}$ ); 1: airway hyperresponsiveness (PD20 $\leqslant 1 \mathrm{mg}$ ); 0 : interval since removal from exposure $\geqslant 10 \mathrm{yrs} ; 1$ : interval since removal from exposure $<10$ yr; 0 : no current inhaled steroids; 1: yes current inhaled steroids; B: regression coefficient; OR: odds ratio; CI: 95\% confidence interval.

\section{Discussion}

In this study the clinical picture of 87 subjects with TDIinduced asthma and the outcome of the subjects at follow-up examination are described. The outcome of isocyanateinduced asthma has been investigated previously [3-11]. However, this study offers additional interest. Indeed, the population was rather large, had been exposed to the same chemical, i.e. TDI, was employed in workplaces with similar characteristics, the diagnosis was made by specific inhalation challenge in $100 \%$ of the cases and the follow-up time was long. Thus, the study offers the opportunity to further characterise the natural history of a very common type of OA and to improve the understanding of the natural history of adult-onset asthma.

This study confirms the features of isocyanate asthma. The latent period between onset of exposure and onset of symptoms is prolonged, the proportion of atopic subjects and of current smokers is low, and the late asthmatic reaction is very common. Interestingly, the proportion of atopic subjects and current smokers did not change at follow-up visit, suggesting the absence of an increase in atopic status after many years from the diagnosis of OA caused by a low molecularweight agent such as TDI. Even though a lower percentage of symptomatic subjects at follow-up examination was observed, they were subjects that had been removed from exposure, not subjects who continued in their primary workplace. However, it should be noted that $60 \%$ of subjects removed for $>10$ yrs complained of asthmatic symptoms and $\sim 60 \%$ of workers needed therapy with bronchodilators, whereas $\sim 20 \%$ of subjects used inhaled glucocorticoids.

These findings confirm the poor clinical outcome of TDIinduced asthma and are in agreement with the results of PIIRILA et al. [11]. Recently, these authors performed a longterm follow-up study on subjects with isocyanate-induced asthma. They examined 95 subjects with hexamethylene diisocyanate (HDI)-, 96 subjects with diphenylmethane diisocyanate (MDI)- and 42 subjects with TDI-induced asthma ( $17 \%$ of the subjects). They found that the persistence of symptoms was mostly associated with TDI-induced asthma, a link confirmed by the finding that TDI patients used more medication than patients with HDI- and MDIinduced asthma. In the study by PIIRILA et al. [11], the worsening of lung function could be linked to the high percentages (74 and $60.5 \%$ ) of smokers at diagnosis and at follow-up, whereas in the present study, even though a deleterious effect of smoking on lung volumes at follow-up examination was found, it is emphasised that the percentage of smokers was very low (8 and $6.9 \%$ respectively at diagnosis and at follow-up). Another potential mechanism for the worsening in lung function observed by PIIRILA et al. [11] is the possibility that active cigarette smoking impairs the efficacy of short-term inhaled corticosteroid treatment in mild asthma [17].

In agreement with previously reported findings [18, 19], it was shown that level of airway responsiveness to methacholine at time of diagnosis is a predictor of the persistence of airway hyperresponsiveness. PERFETTI et al. [18] examined subjects with $\mathrm{OA}$ due to both high and low molecular weight agents and found that subjects removed from exposure for $>5$ yrs showed better prognostic figures than those reported in most follow-up studies up to 5 yrs after cessation of exposure, showing that the majority of subjects were symptomatic and hyperresponsive to methacholine.

The present study confirms, at least in part, these findings. Even though the level of significance was borderline, it was also shown that the duration of follow-up (for $>10 \mathrm{yrs}$ ) is a factor that affects airway responsiveness to methacholine. 
At follow-up examination, a lower proportion of subjects exhibited airway hyperresponsiveness and a lower degree of hyperresponsiveness was observed in the group removed from exposure for $>10 \mathrm{yrs}$. In the present study, the effects of methodological problems were avoided by ensuring instruments, technicians and protocols for delivering methacholine were the same at both diagnosis and follow-up visits. However, it must also be emphasised that a large part $(60 \%)$ of the group of subjects removed for $>10$ yrs complained of asthmatic symptoms and that the lung volumes were significantly lower at follow-up after adjusting for age.

The present study did not allow evaluation of the use of anti-inflammatory drugs for asthma and of inhaled longacting bronchodilators for asthma started at diagnosis. In many cases, the medication had been discontinued and, in addition, the regular use of inhaled steroids and long-acting bronchodilators has become common only in the last decade. The use of these drugs could only be accounted for at the follow-up visit. As expected, subjects who used long-acting bronchodilators had lower lung volumes and subjects who used inhaled steroids had a lower degree of airway hyperresponsiveness to methacholine.

The type of asthmatic reaction did not have a prognostic value in the present study. The influence of the type of reaction on the outcome has been controversial $[4,5]$. In a previous study, the authors suggested that the late reaction and the severity of the reaction could be related to the persistence of sensitisation to isocyanates [7]. At variance with this study, the larger size of the population sample examined here and the long follow-up time allow the authors to conclude that the type of asthmatic reaction is not an important predictor for the persistence of the disease. More recently, evidence has been presented that the outcome of specific airway responsiveness to occupational agents may be different from the outcome of nonspecific airway responsiveness [19].

Among the many risk markers associated with susceptibility for the development of TDI asthma, the ability to cope with oxidative stress has been studied recently [13]. Evidence has been presented that TDI exposure might cause oxidative stress at the epithelial surface [20]. Defects in antioxidant defences could contribute to both the susceptibility of sensitisation and the persistence of TDI-induced asthma. To support this hypothesis, a critical role for the glutathione-Stransferase locus (GSTP1) gene product has been demonstrated recently [21]. Homozygosity for the $\mathrm{Val}^{105}$-encoding alleles confers protection against the development of the asthma-associated phenotype airway hyperresponsiveness and the protective effect increased in proportion to the duration of exposure to TDI.

In conclusion, the present study showed a poor prognosis of toluene diisocyanate-induced asthma. The long-term follow-up revealed that both asthmatic symptoms and airway hyperresponsiveness to methacholine persisted or improved slowly for $>10 \mathrm{yrs}$ after the workers left the workplace and ceased being exposed to isocyanates entirely. A more favourable outcome was associated with a better lung function, a lower degree of airway hyperresponsiveness to methacholine and a longer interval from cessation of exposure.

\section{References}

1. Mapp CE, Butcher BT, Fabbri LM. Polyisocyanates and their prepolymers. In: Bernstein IL, Chan-Yeung M, Malo J-L, Bernstein DI, eds. Asthma in the Workplace. New York, Dekker, 1999; pp. 457-478.

2. Mapp CE, Boschetto P, Dal Vecchio L, et al. Occupational asthma due to isocyanates. Eur Respir J 1988; 1: 273-279.

3. Park HS, Nahm DH. Prognostic factors for TDI-induced occupational asthma after removal from exposure. Clin Exp Allergy 1997; 27: 1145-1150.

4. Paggiaro PL, Loi AM, Rossi O, et al. Follow-up study of patients with respiratory disease due to toluene diisocyanate. Chest 1984; 14: 463-469.

5. Lozewicz S, Assoufi BK, Hawkins R, et al. Outcome of asthma induced by isocyanates. Br J Dis Chest 1987; 81: 14-22.

6. Rosenberg N, Garnier R, Rousselin X, et al. Clinical and socioprofessional fate of isocyanate-induced asthma. Clin Allergy 1987; 17: 55-61.

7. Mapp CE, Chiesura Corona P, De Marzo N, et al. Persistent asthma due to isocyanates. A follow-up study of subjects with occupational asthma due to toluene diisocyanate (TDI). Am Rev Respir Dis 1988; 137: 1326-1329.

8. Banks DE, Rando RJ, Barkman HW Jr. Persistence of toluene diisocyanate-induced asthma despite negligible workplace exposures. Chest 1990; 97: 121-125.

9. Pisati F, Baruffini A, Zedda S. Toluene diisocyanate induced asthma: outcome according to persistence or cessation of exposure. Br J Ind Med 1993; 50: 60-64.

10. Tarlo S, Banks D, Liss G, Broder I. Outcome determinants for isocyanate induced occupational asthma among compensation claimants. Occup Environ Med 1997; 54: 756-761.

11. Piirila PL, Nordman H, Keskinen HM, et al. Long-term follow-up of hexamethylene diisocyanate-, diphenylmethane diisocyanate-, and toluene diisocyanate-induced asthma. Am J Respir Crit Care Med 2000; 162: 516-522.

12. Malo JL, Chan-Yeung M. Occupational asthma. J Allergy Clin Immunol 2001; 108: 317-328.

13. Park HS, Frew AJ. Genetic markers for occupational asthma. J Allergy Clin Immunol 2002; 109: 774-776.

14. Fabbri LM, Chiesura-Corona P, Dal Vecchio, et al. Prednisone inhibits the late asthmatic reaction and airway responsiveness in toluene diisocyanate sensitized subjects. Am Rev Respir Dis 1985; 132: 1010-1014.

15. American Thoracic Society. Evaluation of impairment/ disability secondary to respiratory disorders. Am Rev Respir Dis 1986; 133: 1205-1209.

16. Commissions des Communautes Europeennes (CECA). Tables de reference pour les examens spirometriques. Luxembourg: Office des publications officielle des Communautes Europeennes 1971 .

17. Chalmers GW, Macleod KJ, Little SA, et al. Influence of cigarette smoking on inhaled corticosteroid treatment in mild asthma. Thorax 2002; 57: 2226-2230.

18. Perfetti L, Cartier A, Ghezzo H, et al. Follow-up of occupational asthma after removal from or diminution of exposure to the responsible agent. Relevance of the length of the interval from cessation of exposure. Chest 1998; 114: 398-403.

19. Lemière C, Cartier A, Malo JL, Lehrer SB. Persistent specific bronchial reactivity to occupational agents in workers with normal nonspecific bronchial reactivity. Am J Respir Crit Care Med 2000; 162: 976-980.

20. Elms J, Beckett PN, Griffin P, et al. Mechanisms of isocyanate sensitization. An in vitro approach. Toxicol In Vitro 2001; 15: 631-634.

21. Mapp CE, Fryer AA, De Marzo N, et al. Glutathione Stransferase GSTP-1 is a susceptibility gene for occupational asthma induced by isocyanates. J Allergy Clin Immunol 2002; 109: 867-872.
Acknowledgements. The authors would like to
thank the subjects who participated in this study. They would also like to thank F. Parise for her valuable contribution in revising the manuscript. 